\title{
inventions
}

Editorial

\section{A New Article Type: Patent Summary}

\author{
Chien-Hung Liu ${ }^{1}$ and Inventions Editorial Office ${ }^{2, *}$ \\ 1 Department of Mechanical Engineering, National Chung Hsing University, 250 Kuo Kuang Rd., \\ Taichung 402, Taiwan; carus@dragon.nchu.edu.tw \\ 2 MDPI AG, St. Alban-Anlage 66, 4052 Basel, Switzerland \\ * Correspondence: inventions@mdpi.com; Tel.: +41-61-683-77-34
}

Received: 23 January 2018; Accepted: 23 January 2018; Published: 25 January 2018

We are pleased to announce a new article type, "Patent Summary", for Inventions. As you may know, patent descriptions are usually written in complex language; however this new type of article provides the opportunity for a simple summary for a research-based audience.

The novelty and highlights of a patent need to be clearly listed in the abstract, such as the problems that the patent aims to solve, advantages, optimization results, and the significance of the design. Information about potential applications can go in the discussion. In addition, the details of the patents should be written clearly in the "Patents", section while the patent rights and content confidentiality need to be listed in the "Conflicts of Interests" section.

As a result, the new type of paper will help researchers promptly and rapidly understand the contents of specific patents. A peer-review process is required in this section.

We welcome patent summaries on all kinds of scientific fields, especially on engineering and product development processes. Topics include, but are not limited to patent-based/extended/reviewed inventions in engineering, systems, devices, methods, compositions, processes, products, design, and advanced technologies.

(C) 2018 by the authors. Licensee MDPI, Basel, Switzerland. This article is an open access article distributed under the terms and conditions of the Creative Commons Attribution (CC BY) license (http:/ / creativecommons.org/licenses/by/4.0/). 